\title{
Spontaneous thrombosis in giant intracranial aneurysms
}

\author{
IAN R WHITTLE, NICHOLAS W DORSCH, MICHAEL BESSER \\ From the Department of Neurosurgery, Royal Prince Alfred Hospital, Sydney, Australia
}

SUMMARY Twelve patients in a series of 22 with giant intracranial aneurysms demonstrated neuroradiological features of partial or total spontaneous intra-aneurysmal thrombosis. The presence of this intra-aneurysmal clot significantly altered the computed tomographic appearance of the giant aneurysm. Massive intra-aneurysmal thrombosis did not protect against subarachnoid haemorrhage and the likelihood of rupture of a clot containing giant aneurysm was not significantly different from that of a non-thrombosed giant aneurysm. Although parent artery occlusion from a thrombosed giant aneurysm, and massive aneurysmal thrombosis leading to the formation of giant serpentine aneurysm were documented, these are rare epiphenomena. The risk of embolisation from a partially thrombosed giant aneurysm, which was documented in one case, would appear to be greater than that from a non-thrombosed giant aneurysm. The findings in this series, and a review of literature, suggest that the presence of intra-aneurysmal clot in giant intracranial aneurysms has little prognostic significance and does not alter the management or outcome after treatment.

Since Morley and Barr $^{1}$ defined intracranial aneurysms with a diameter of greater than $2 \cdot 5 \mathrm{~cm}$ as giant, these lesions have become recognised as a discrete neuropathological entity. Recent publications on giant intracranial aneurysms have documented their diagnostic neuroradiological features ${ }^{2-4}$ and the trends in their neurosurgical management. ${ }^{5-8}$ An interesting feature, commonly noted in these studies, is the propensity for intra-aneurysmal thrombosis, either total or more commonly partial. This epiphenomenon was initially reported by Lyell ${ }^{9}$ as an incidental finding at the necropsy of a man who had died of unrelated head injuries. Subsequently, additional case reports have documented further relevant clinical, neuroradiological and surgical manifestations of spontaneous thrombosis in giant intracranial aneurysms. ${ }^{10-14}$ However, despite the pioneering work of Black and German ${ }^{15}$ on intraaneurysmal thrombogenesis there has been no systematic study of this phenomenon in giant

Presented at 55th General Scientific Meeting of the Royal Australasian College of Surgeons, Christchurch, New Zealand, 29 January 1982.

Address for reprint requests: Dr Ian $\mathrm{R}$ Whittle, Neurosurgery Department, Royal Prince Alfred Hospital, Missenden Road, Camperdown NSW 2050, Australia.

Received 1 July 1982

Accepted 9 August 1982 intracranial aneurysms despite its frequent occurrence. The clinical significance of this pathophysiological process has been further clouded by contradictory statements in the literature..$^{51316}$

In this paper the authors examine the diagnostic features and incidence of intra-aneurysmal thrombosis in 22 patients with giant intracranial aneurysms. The significance of this epiphenomenon was assessed with particular reference to the problems of subarachnoid haemorrhage, thromboembolism and parent artery occlusion from a thrombosing giant intracranial aneurysm. Our conclusions are compared to reported data, and implications with respect to neurosurgical management are discussed.

\section{Patients and methods}

During the period 1976-81, 302 patients with a diagnosis of intracranial aneurysm were admitted to the neurosurgical unit at the Royal Prince Alfred Hospital. Diagnosis was confirmed in each case by a combination of cerebral angiography, cerebral computed tomography (CT) or postmortem examination. Review of these studies together with clinical and operative records revealed that 22 of the patients had aneurysms of giant dimensions $(>2.5 \mathrm{~cm}$ diameter). The neuroradiographic studies of these patients were examined in detail for evidence of intra-aneurysmal thrombosis. Angiographic features suggestive of significant intra-aneurysmal thrombosis were irregularity and 
asymmetry of the aneurysmal lumen, decrease in the size of the aneurysmal lumen on serial angiography, and disparity in the size and shape of the aneurysm as suggested by the angiographic and CT data. The CT features suggestive of partial or total giant intracranial aneurysm thrombosis were mixed high density attenuation values within the aneurysmal lumen, the presence or absence of "Target Sign" 2 and peripheral ring enhancement after contrast administration, and curvilinear calcification of the aneurysmal wall. Neuroradiographic data in each case was correlated with the clinical course and operative or postmortem findings. An attempt was made to evaluate the significance of intra-aneurysmal thrombus with respect to clinical parameters such as subarachnoid haemorrhage, parent artery occlusion, thrombo-embolism and patient morbidity and mortality.

\section{Results}

\section{Radiological}

Twelve $(55 \%)$ of the 22 patients with a giant intracranial aneurysm demonstrated complimentary angiographic and CT features of significant intraaneurysmal thrombosis (table 1). There was no particular preference in site of the distribution of the non-thrombosed and thrombus-containing giant intracranial aneurysms (table 2). On CT scanning the 12 thrombus-containing giant intracranial aneurysms appeared as lesions of variable shape and with mixed attenuation values that were always higher than the surrounding brain. "Target Sign" and peripheral ring enhancement after contrast administration, were seen in $10(83 \%)$, and seven $(58 \%)$ cases respectively.
Table 2 Locations of the 22 giant intracranial aneurysms in the series, and incidence of intra-aneurysmal thrombus with locus

\begin{tabular}{|c|c|c|c|}
\hline \multirow[t]{2}{*}{ Locus } & \multirow[t]{2}{*}{ No } & \multicolumn{2}{|c|}{ Intra-aneurysmal thrombus } \\
\hline & & Present & None \\
\hline $\begin{array}{l}\text { Cavernous carotid } \\
\text { Carotid-communicating/ }\end{array}$ & 3 & 2 & 1 \\
\hline bifurcation/ophthalmic & 4 & 2 & 2 \\
\hline Anterior cerebral A & 1 & 0 & 1 \\
\hline Middle cerebral A & 10 & 5 & 5 \\
\hline Basilar-bifurcation & 4 & 3 & 1 \\
\hline Total & 22 & 12 & 10 \\
\hline
\end{tabular}

Two patients (17\%) did not demonstrate a "Target Sign", one because of complete aneurysmal thrombosis (Case 4), and the other (Case 6) because the residual aneurysmal lumen was too small for the resolution of the CT scanner. Calcification of the aneurysm wall was visualised in six (50\%) cases.

Disparity in the size and shape of the angiographically demonstrated aneurysm and CT lesion occurred in all 12 cases (figs 1,2$)$. In five $(42 \%)$ cases the angiographically demonstrated lumen appeared irregular in outline, and in seven (58\%) cases the angiograms suggested the presence of small or moderate $(<2.5 \mathrm{~cm})$ sized aneurysms. One totally thrombosed aneurysm (Case 4) appeared as an avascular mass. This aneurysm was associated with ipsilateral carotid artery thrombosis that extended down to the carotid bifurcation in the neck, and was the only case of parent artery occlusion in the series.

Table 1 Major angiographic and computed tomographic findings in the 12 patients with partially and totally thrombosed giant intracranial aneurysms

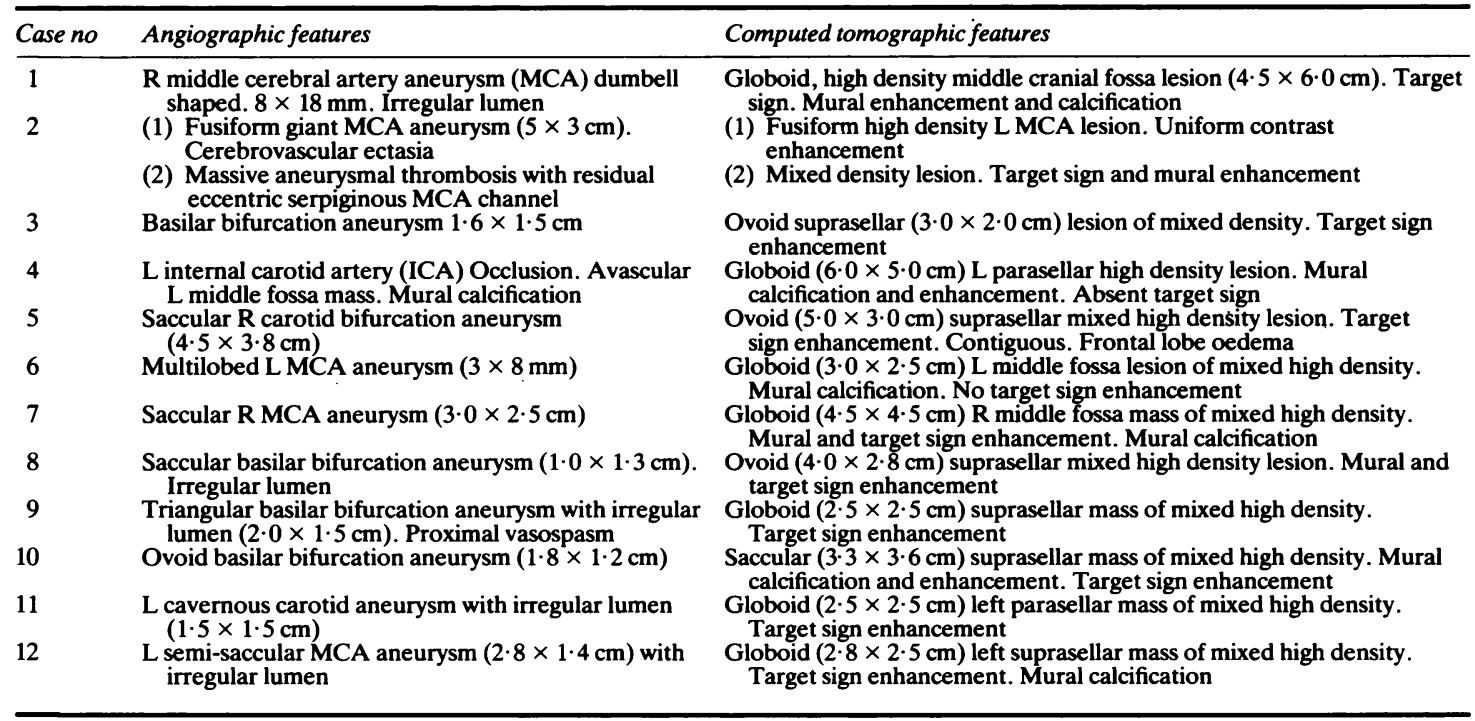




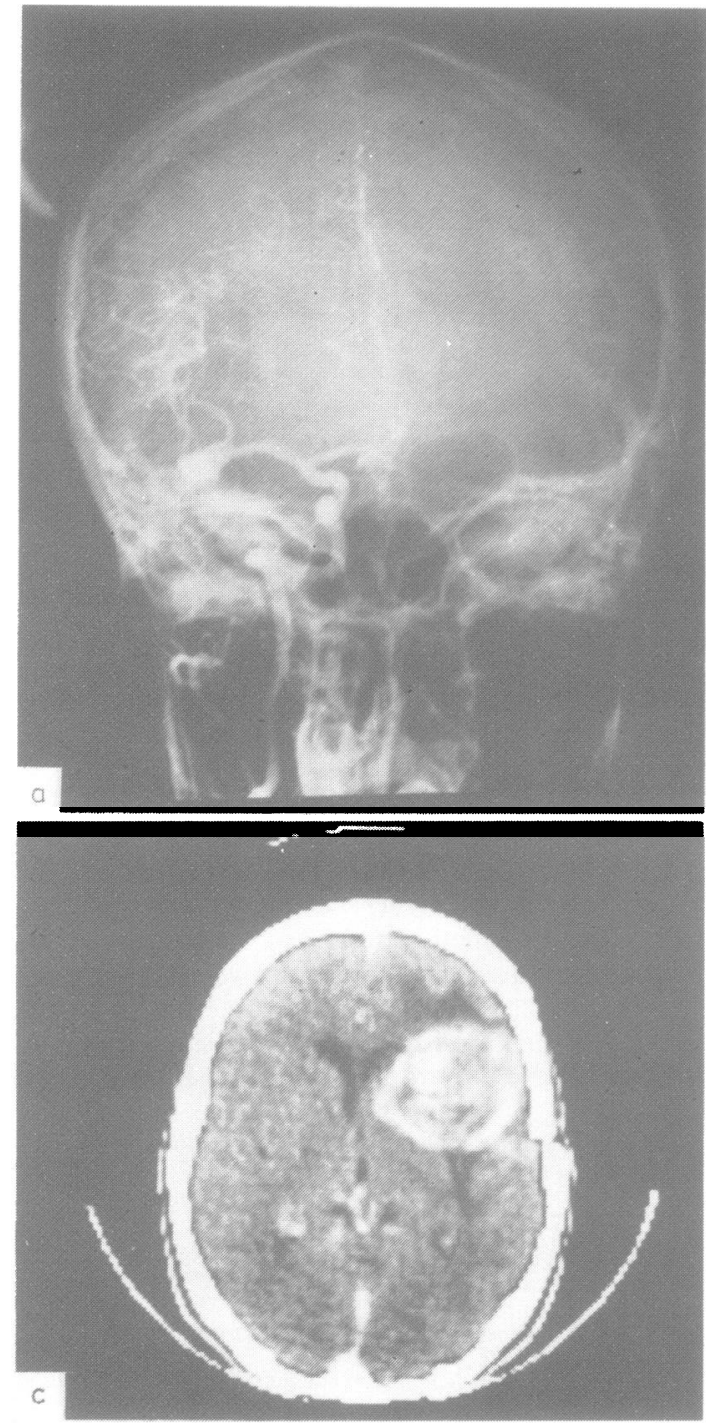

There was one case (Case 2) documented with serial angiography, of almost complete spontaneous giant intracranial aneurysm thrombosis, in a previously non-thrombus-containing giant fusiform middle cerebral artery aneurysm. The middle cerebral artery, remained patent as a serpiginous channel through the avascular mass, thus resulting in the formation of a "Giant Serpentine aneurysm"10"11 (fig $3)$. CT studies suggested a similar process had occurred in another patient (Case 7); however, severe contrast allergy precluded angiographic documentation.

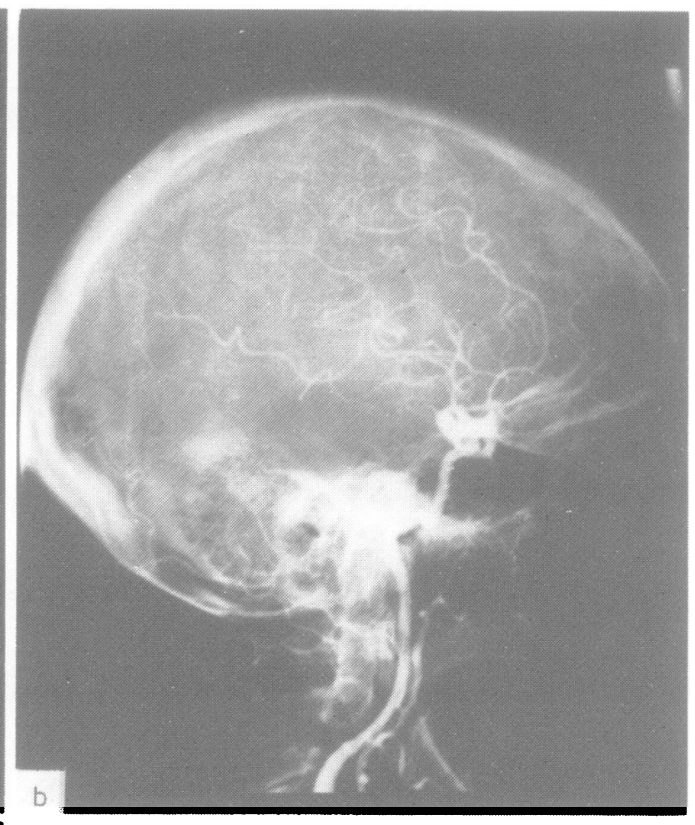

Fig 1 Carotid angiograms and enhanced CT scan of Case 1. The anteroposterior (a) and lateral (b) carotid angiograms show a dumbell-shaped left middle cerebral artery aneurysm of approximate dimensions $0.8 \times 1.8 \mathrm{~cm}$. Although there is distortion of the $M_{3}$ segment, and a suggestion of a larger contiguous aneurysmal cavity, the CTscan (c) reveals the true dimensions of the lesion. This study also demonstrates the mural calcification and mixed attenuation values of the intra-aneurysmal thrombus.

\section{Clinical}

Symptoms and signs leading to clinical presentation of the 12 patients with thrombus-containing giant intracranial aneurysms are listed in table 3 . Symptomatology emanating from the intracranial mass effect of the aneurysm (viz progressive focal neurological deficit, focal epilepsy, intellectual impairment and headache) accounted for presentation in eight $(67 \%)$ patients. However four of these patients had no focal neurological deficit on clinical examination. Headache was the most commonly recorded symptom, being documented in $10(83 \%)$ patients in the weeks prior to admission. There was one case of recurrent faciobrachial paresis and dysphasia due to embolism from a largely thrombosed giant left middle cerebral artery aneurysm (Case 2). Four (44\%) of the nine patients with partially thrombosed giant intracranial aneurysms at presentation had experienced 


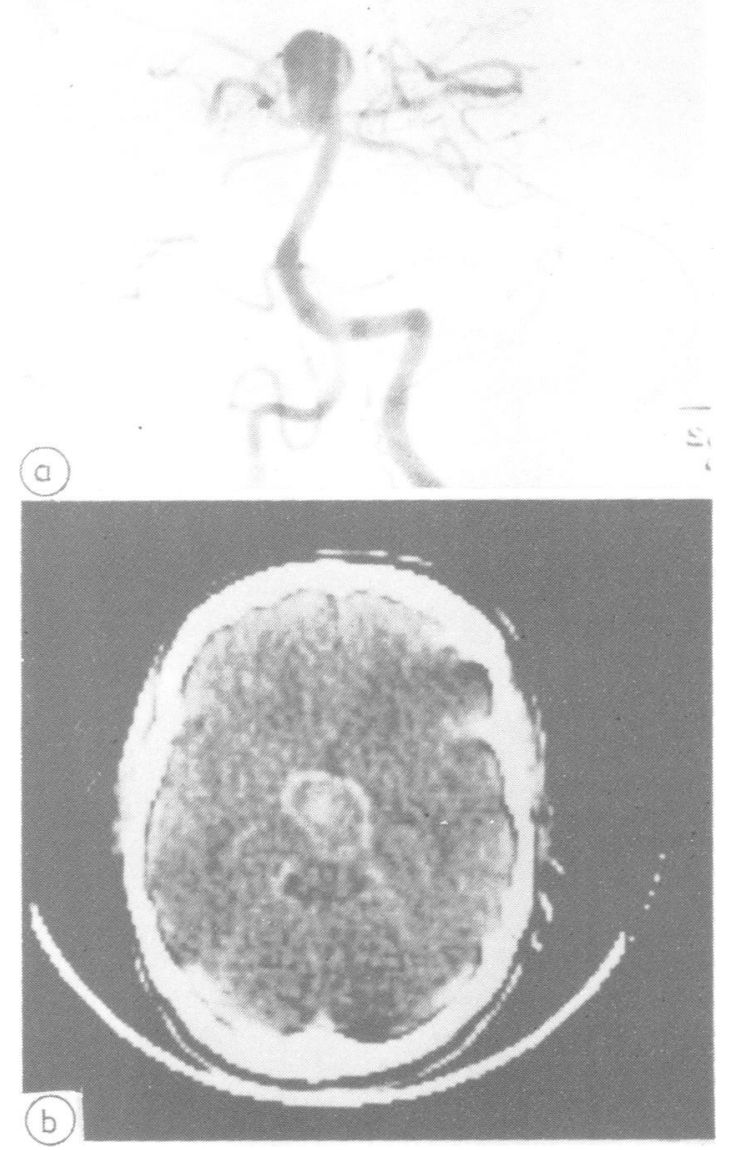

Fig 2 Vertebrobasilar angiogram (subtraction film) and CT scan of Case 10. The anteroposterior angiographic film (a) shows an ovoid basilar bifurcation aneurysm of approximately $1.8 \times 1.2 \mathrm{~cm}$, with a regular lumen. The $C T$ scan (b) again reveals the true dimensions of the lesion. A central "Target sign", mural calcification and contrast enhancement of the aneurysm wall are also demonstrated.

subarachnoid haemorrhage and it was the presenting syndrome in three of these cases. Subarachnoid haemorrhage had occurred in five $(42 \%)$ of the 12 patients who at presentation had non-thrombosed giant intracranial aneurysms. This difference in the incidence of haemorrhage from non-thrombosed and thrombus-containing giant intracranial aneurysms is not significant. In those patients presenting with subarachnoid haemorrhage the mortality was $60 \%$ for non-thrombosed and $66 \%$ for thrombuscontaining giant intracranial aneurysms.
Overall there was no significant difference in age, sex distribution, morbidity, mortality and incidence of definitive aneurysm surgery in the patients with non-thrombosed and thrombus-containing giant intracranial aneurysms (table 4). Preoperative management which consisted of a routine regime of anti-fibrinolytic, anticonvulsant and steroid therapy, was not influenced by the presence of intraaneurysmal clot.

\section{Pathological examination}

The neuroradiographic diagnosis of significant intraaneurysmal thrombosis was confirmed at operation in six patients (Case 1, 4-6, 10) and in one (Case 2) at necropsy. Macroscopic and histopathological examination of the aneurysmal fundi removed at operation (Case 4-6) or necropsy (Case 2) revealed lamination and variable organisation of the thrombus in all cases (fig 4).

\section{Discussion}

Spontaneous intra-aneurysmal thrombosis is a well documented phenomenon that, as in our series, has been noted in approximately $50 \%$ of giant intracranial aneurysms 235617 as well as being the topic of many case reports. ${ }^{9-14}$ This high incidence of thrombus formation within giant intracranial aneurysms is related to a critical ratio, between aneurysmal volume and aneurysmal neck size, below which intra-aneurysmal thrombosis occurs. ${ }^{15}$ Although other biophysical and dynamic parameters contribute to the delicate balance between thrombogenesis and thrombolysis within the aneurysm (vide infra), the volume/orifice ratio would appear to be the major factor. ${ }^{15}$

Computed tomography has considerably facilitated the diagnosis of partially or totally thrombosed giant intracranial aneurysms. Although intra-aneurysmal thrombus significantly alters the CT appearance, the pathognomonic features of these lesions have recently been well documented..$^{2-4}$ This variable appearance may, however, simulate many different intracranial lesions, the differential diagnosis of which includes germinoma, pituitary adenoma, meningioma, glioma, acoustic neuroma, epidermoid cyst and craniopharyngioma. ${ }^{2}$ Disparity in the size and shape of the lesion as visualised by CT and cerebral angiography is diagnostic of partial or total giant intracranial aneurysm thrombosis. Angiography may be non-diagnostic or frequently misleading with respect to the aneurysm size if significant thrombosis has occurred. The clinical correlation is also variable since, although $47 \%$ of patients with giant intracranial aneurysms may present with subarachnoid haemorrhage, the 

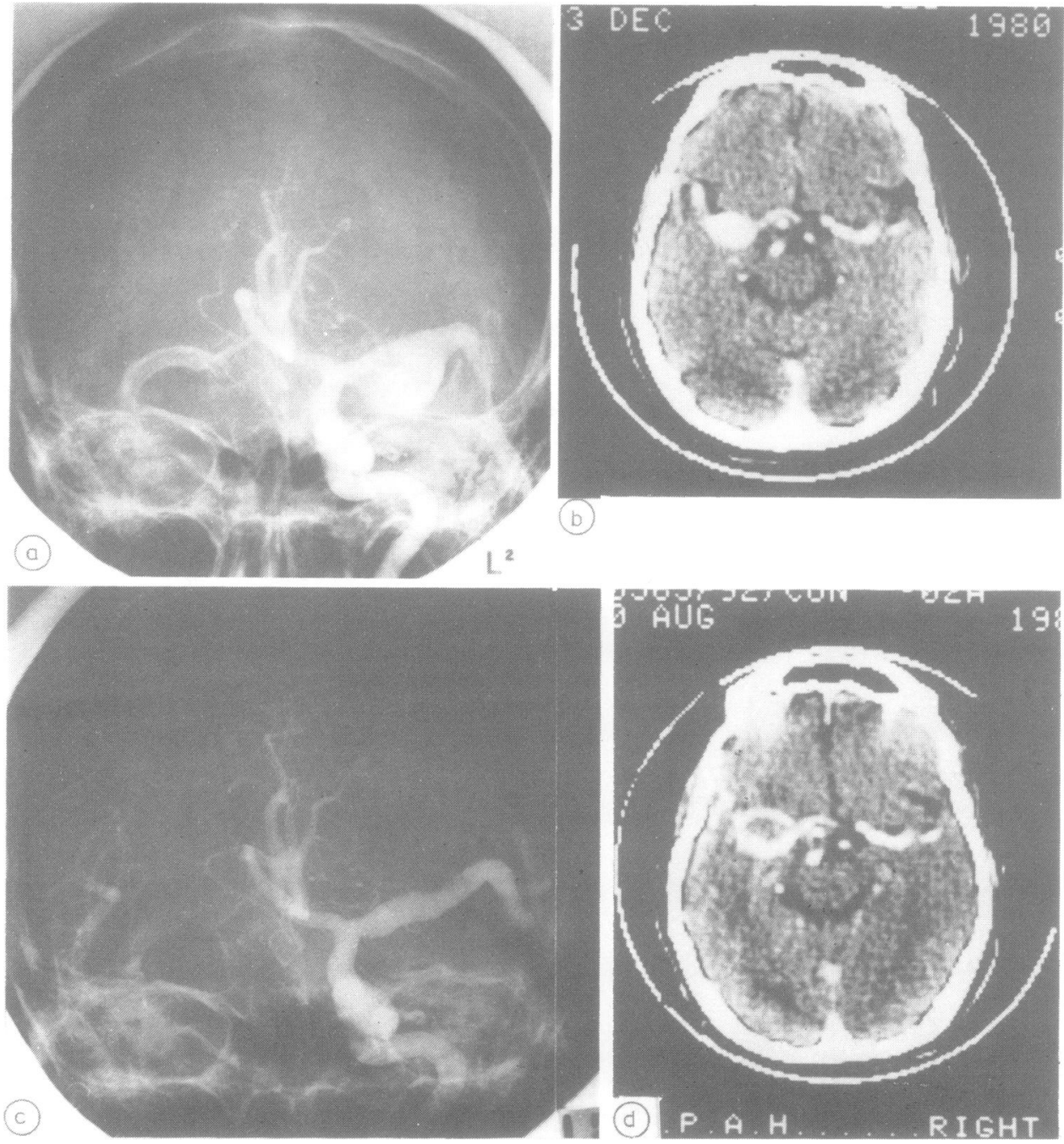

Fig 3 Sequential carotid angiograms and CT scans of Case 2 showing the evolution of a giant serpentine aneurysm from a previously non-thrombus-containing giant fusiform middle cerebral artery aneurysm. Carotid angiography (a) and enhanced CT scan (b), performed in December, 1980 reveal a giant fusiform left middle cerebral artery aneurysm, and diffuse cerebrovascular ectasia. Subsequent studies performed in August, 1981 (c, d) following the onset of headaches and transient ischaemic attacks, reveal extensive thrombosis of the aneurysm, with preservation of serpiginous middle cerebral arterial lumen.

remaining patients present with neurological symptoms and signs that are either non-specific or related to intracranial mass effect. $^{5-8}$ The clinical significance of intra-aneurysmal thrombus formation in giant intracranial aneurysms has not previously been studied, although contradictory statements have appeared in the neurosurgical literature, particularly with regard to its efficacy in the prevention of subarachnoid haemorrhage.
Organisation of the thrombus has been claimed to provide a skeletal lattice that protects against haemorrhage ${ }^{1316}$ and enhances enlargement of the aneurysm to giant dimensions. ${ }^{18}$ Conversely Drake ${ }^{5}$ has suggested that even massive intra-aneurysmal clot does not protect against haemorrhage. The results in this small series and data extrapolated from the larger series of Drake ${ }^{5}$ and Hosobuchi, ${ }^{6}$ would support the contention that unless the giant intracranial 
Table 3 Clinical symptomatology and signs together with treatment and outcome of the twelve patients with partially or totally thrombosed giant intracranial aneurysm

\begin{tabular}{|c|c|c|c|c|c|c|c|}
\hline $\begin{array}{l}\text { Case } \\
\text { no }\end{array}$ & $\begin{array}{l}\text { Age } \\
(y r)\end{array}$ & Sex & $\begin{array}{l}\text { Giant } \\
\text { aneurysm }\end{array}$ & Thrombosis & Symptom & Focal signs & Outcome comments \\
\hline 1 & 47 & $\mathbf{F}$ & R MCA & Extensive & $\begin{array}{l}\text { Jacksonian epilepsy } \\
\text { (previous sub- } \\
\text { arachnoid } \\
\text { haemorrhage) }\end{array}$ & Nil & $\begin{array}{l}\text { Aneurysm clipped. Well. } \\
\text { Occasional seizures }\end{array}$ \\
\hline 2 & 59 & $\mathbf{M}$ & L MCA & Extensive & $\begin{array}{l}\text { Headaches, uncinate } \\
\text { seizure, intellectual } \\
\text { impairment }\end{array}$ & Nil & $\begin{array}{l}\text { Aneurysm wrapped. Progressive } \\
\text { deterioration. Recurrent emboli, } \\
\text { transient ischaemic attacks. Died } \\
\text { with pulmonary emboli }\end{array}$ \\
\hline 3 & 66 & $\mathbf{F}$ & $\begin{array}{l}\text { Basilar } \\
\text { bifurcation }\end{array}$ & Partial & $\begin{array}{l}\text { Subarachnoid } \\
\text { haemorrhage, } \\
\text { Prodromal headache } \\
\text { (1 month) }\end{array}$ & $\begin{array}{l}\text { Subarachnoid } \\
\text { haemorrhage, } \\
\text { grade } 3\end{array}$ & Rebleed. Died day 10 \\
\hline 4 & 26 & $\mathbf{M}$ & $\begin{array}{l}\text { L cavernous } \\
\text { ICA }\end{array}$ & Total & $\begin{array}{l}\text { Headache, } \\
\text { ophthalmoplegia }\end{array}$ & $\begin{array}{l}\text { L proptosis, } \\
\text { ophthalmoplegia, } \\
\text { facial dysaesthesia }\end{array}$ & $\begin{array}{l}\text { Aneurysmotomy, thrombectomy. } \\
\text { Well }\end{array}$ \\
\hline 5 & 56 & $\mathbf{F}$ & $\begin{array}{l}\mathrm{R} \text { I carotid } \\
\text { bifurcation }\end{array}$ & Partial & $\begin{array}{l}\text { 1/52 headache, } \\
\text { intellectual } \\
\text { impairment }\end{array}$ & Nil & $\begin{array}{l}\text { Aneurysmectomy. Clipping. } \\
\text { Unchanged intellect }\end{array}$ \\
\hline 6 & 57 & $\mathbf{M}$ & L MCA & Extensive & $\begin{array}{l}1 / 12 \text { progressive } R \\
\text { brachial paresis }\end{array}$ & $\begin{array}{l}\text { Brachial paresis, } \\
\text { dysphasia }\end{array}$ & $\begin{array}{l}\text { Aneurysmectomy and throm- } \\
\text { bectomy. Dysphasia. } R \text { hemi- } \\
\text { paresis. Post-op. seizure } \times 1\end{array}$ \\
\hline 7 & 47 & $\mathbf{F}$ & R MCA & Extensive & Headache & $\mathrm{Nil}$ & Well. Aneurysm wrapped and glued \\
\hline 8 & 63 & $\mathrm{~F}$ & $\begin{array}{l}\text { L carotid } \\
\text { bifurcation }\end{array}$ & Extensive & $\begin{array}{l}\text { Subarachnoid } \\
\text { haemorrhage. } \\
\text { Grand mal } \\
\text { seizures. Headache. } \\
\text { Intellectual impair- } \\
\text { ment }\end{array}$ & $\begin{array}{l}\text { Subarachnoid } \\
\text { haemorrhage. Grade } \\
3 \text { hemiparesis } \\
\text { (right), intellectual } \\
\text { impairment, oculo- } \\
\text { motor palsy }\end{array}$ & $\begin{array}{l}\text { Aneurysm clipped. Hemiparesis } \\
\text { resolved. Intellect improved } \\
\text { after ventriculoperitoneal } \\
\text { shunting }\end{array}$ \\
\hline 9 & 45 & $\mathbf{F}$ & $\begin{array}{l}\text { Basilar } \\
\text { bifurcation }\end{array}$ & Partial & $\begin{array}{l}\text { Subarachnoid } \\
\text { haemorrhage. } \\
\text { Prodromal } \\
\text { headaches }\end{array}$ & $\begin{array}{l}\text { Subarachnoid } \\
\text { haemorrhage, } \\
\text { grade } 5\end{array}$ & Rebleed. Died day 9 \\
\hline 10 & 50 & $\mathbf{F}$ & $\begin{array}{l}\text { Basilar } \\
\text { bifurcation }\end{array}$ & Extensive & $\begin{array}{l}\text { Headache. Progres- } \\
\text { sive L hemiparesis }\end{array}$ & Mild L hemiparesis & $\begin{array}{l}\text { Aneurysm clipped. Mild residual L } \\
\text { hemiparesis }\end{array}$ \\
\hline 11 & 53 & $\mathrm{~F}$ & $\begin{array}{l}\text { L cavernous } \\
\text { carotid }\end{array}$ & Extensive & Ophthalmoplegia $1 / 52$ & Ophthalmoplegia & $\begin{array}{l}\text { ICA ligation with BTA-MCA } \\
\text { bypass. Ophthalmoplegia } \\
\text { unchanged }\end{array}$ \\
\hline 12 & 21 & $\mathbf{M}$ & L MCA & Extensive & $\begin{array}{l}\text { Non-haemorrhagic } \\
\text { syncope }\end{array}$ & $\mathbf{R}$ hemiplegia & $\begin{array}{l}\text { Currently rehabilitating. CT scan } \\
\text { show focal capsular infarction }\end{array}$ \\
\hline
\end{tabular}

aneurysm is totally thrombosed, intra-aneurysmal clot does not protect against subarachnoid haemorrhage. The incidence of subarachnoid haemorrhage from partially thrombosed giant intracranial aneurysms in the latter two series was $40 \%$ compared to an incidence of subarachnoid haemorrhage from non-thrombosed giant intracranial aneurysms of $48 \%$ and $40 \%$ respectively. ${ }^{56}$ In both these series, as in ours, these differences are not significant.

The incidence of haemorrhage from thrombuscontaining giant intracranial aneurysms may be spuriously elevated by the detection of thrombus formed after the haemorrhage. Altered haemodynamics at the time of haemorrhage and subsequent cerebral vasospasm could enhance intraaneurysmal vascular stasis. Nonetheless the neuroradiological, operative and post-mortem findings, would suggest that in most cases laminated thrombus antedates the haemorrhage. Peripheral ring enhancement and mural calcification are believed to be related to longstanding aneurysmal thrombosis and clot organisation. ${ }^{10} 18$ Furthermore, thrombus deposition within the aneurysm is nonuniform because of flow dynamics, turbulence patterns and the pattern of endothelial damage. Consequently, although sections of the giant intracranial aneurysm wall may be fibro-calcific, other segments may be extremely tenuous, and it is from these sites that rupture occurs.

The significance of intra-aneurysmal thrombus in the genesis of thrombo-emboli from a giant intracranial aneurysm is uncertain, mainly because of the infrequency with which, until recently, emboli from aneurysms had been recognised as a cause of transient cerebral ischaemia. In a review of the literature to 1978 only twelve well documented cases from all intracranial aneurysms had been reported. ${ }^{19}$ Reversible ischaemic neurological deficits attributable to emboli emanating from partially thrombosed giant intracranial aneurysms have been documented on several occasions ${ }^{6181921}$ and our Case 
Table 4 Comparative patient profiles showing the incidence of major neurosurgical intervention, mortality and morbidity in patients with non-thrombosed and thrombus containing giant intracranial aneurysms

\begin{tabular}{lll}
\hline & \multicolumn{2}{l}{ Giant aneurysm status } \\
\cline { 2 - 3 } & No thrombus & $\begin{array}{l}\text { Partial/total } \\
\text { thrombosis }\end{array}$ \\
\hline 1 No & 10 & 12 \\
2 Female : male ratio & $8: 2$ & $8: 4$ \\
3 Age (mean \pm SD) yr & $50 \pm 13$ & $50 \pm 10$ \\
4 Operation on aneurysm & & \\
$\quad \begin{array}{l}\text { (clipping, wrapping, glueing, } \\
\text { aneurysmectomy, etc.) }\end{array}$ & 7 & 8 \\
5 Death & 4 & 3 \\
Morbidity & 3 & 3 \\
$\begin{array}{l}\text { No focal neurological deficit } \\
\text { Isolated ophthalmoplegia }\end{array}$ & 2 & 3 \\
Intellectual impairment & 2 & 2 \\
$\quad \begin{array}{l}\text { Epilepsy } \\
\text { Hemiplegia/dysphasia }\end{array}$ & 1 & 0 \\
& 0 & 2 \\
\hline
\end{tabular}

2 is the first report of embolisation from a giant serpentine aneurysm. In one series $59 \%$ of the thrombus-containing giant intracranial aneurysms were associated with distal thrombo-embolism, ${ }^{18}$ in another it was $5 \%,{ }^{6}$ and in the present series the figure is $8 \%$. Paroxysmal ischaemic episodes have, however, been described from non-thrombuscontaining giant intracranial aneurysms $\mathrm{s}^{21}$ and in these cases it has been postulated that the cerebral dysfunction may be attributable to compressive effects of the aneurysm, ipsilateral carotid artery plaques, vasoconstrictor agents (Thromboxane $\mathrm{A}^{2}$, Prostaglandin $G^{2}$ ) activated by turbulence and stasis within the giant intracranial aneurysm, as well as platelet emboli. Platelet deposition is a dynamic process that has recently been documented with radioisotopic technique to occur in giant intracranial aneurysm without radiographically detectable thrombus or clinical symptomatology. ${ }^{18}$ Overall, it would appear that the risk of embolisation is greater from a thrombus-containing giant intracranial aneurysm although the relative incidence of this epiphenomenon awaits documentation.

The probability of parent artery occlusion by propagation of thrombus from a giant intracranial aneurysm would appear to be extremely low. There are two reported cases of parent artery occlusion associated with total spontaneous giant intracranial aneurysm thrombus ${ }^{312}$ one of which is Case 4 of the present series, and one report of partial parent artery occlusion by a partially thrombosed giant intracranial aneurysm. ${ }^{22}$ The rarity of this epiphenomenon despite gross distortion of the parent arterial lumen or its incorporation into the aneurysmal fundus is related to local aneurysmal and arterial haemodynamics. Black and German ${ }^{15}$ demonstrated that intra-aneurysmal blood velocity is inversely related to aneurysmal volume, and that flow into the aneurysm is related to aneurysm neck size. Thus as an aneurysm thromboses the conditions propitious for further thrombosis diminish, and this equilibrium is partly determined by the haemodynamic capabilities of the parent artery. Conversely the dynamics of the jet stream of blood from the parent artery are altered by distortion of the arterial lumen by the aneurysm. The importance of the Coanda Effect has been described in aneurysmal surgery, ${ }^{23}$ and recently it has been postulated as a major factor in the formation of the eccentric serpiginous vascular channels seen in giant serpentine aneurysm. ${ }^{10}$ The giant serpentine

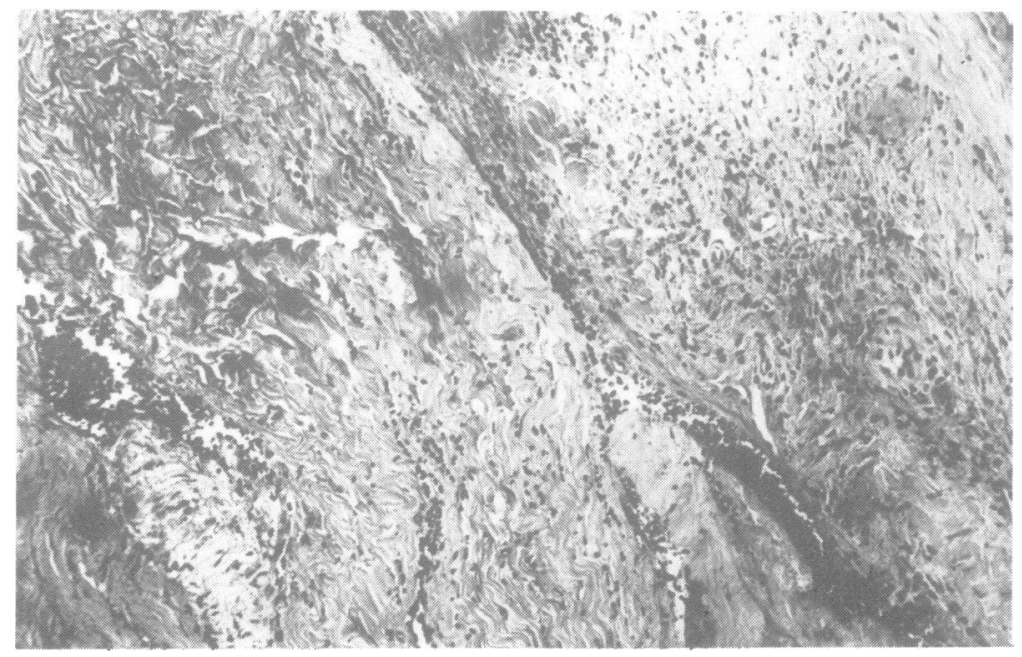

Fig 4 Photomicrograph of a segment of the wall of a giant aneurysm with underlying organised thrombus (Case 4). The tunica adventitia of the aneurysmal wall can be seen in the top right. The underlying mural tissue consists of a hypercellular fibrous stroma, with interspersed capillaries, that merges with the organised thrombus. Vascular sinuses and capillaries are prominent within the clot. $(H \& E \times 100)$ 
aneurysm formed in Case 2 in this series would appear to substantiate this hypothesis, and this case also demonstrates that although massive aneurysmal thrombosis may occur, the parent arterial lumen may be maintained.

Recent reports on the current trends in the neurosurgical management of giant intracranial aneurysm do not differentiate between partially thrombosed and non-thrombosed aneurysms. ${ }^{5-8}$ One may therefore infer that no difference in the clinical presentation, surgical approach, and morbidity and mortality between the two groups has been noted. This would appear to be complemented by the results for these parameters in this series. Thus although partially thrombosed giant intracranial aneurysm may present a diagnostic challenge the subsequent behaviour of these aneurysms, and the principles in their surgical management do not differ significantly from non-thrombosed giant intracranial aneurysms. Totally thrombosed giant intracranial aneurysm, however, pose a different threat to the patient, and the management of these rare aneurysms is well documented. ${ }^{12-14}$

The authors thank Mr GK Vanderfield, Mr JN Segelov and $\mathrm{Mr}$ IH Johnston, neurosurgeons, Royal Prince Alfred Hospital, for permission to include their patients, and Dr TS Lamond and Dr M Schroeder, neuroradiologists, Royal Prince Alfred Hospital, for their radiological studies.

\section{References}

${ }^{1}$ Morley TP, Barr HWK. Giant intracranial aneurysms: diagnosis, course and management. Clin Neurosurg 1969;16:73-94.

${ }^{2}$ Schubiger O, Valavanis A, Hayek J. Computed tomography in cerebral aneurysms with special emphasis on giant intracranial aneurysms. $J$ Comput Assist Tomogr 1980;4:24-32.

${ }^{3}$ O'Neill M, Hope T, Thomson G. Giant intracranial aneurysms: diagnosis with special reference to computerised tomography. Clin Radiology 1980;31: 27-39.

${ }^{4}$ Golding R, Peatfield RC, Shawdon HH, et al. Computer tomographic features of giant intracranial aneurysms. Clin Radiology 1980;31:41-8.
${ }^{s}$ Drake CG. Giant intracranial aneurysms: experience with surgical treatment in 174 cases. Clin Neurosurg 1979;26:12-95.

${ }^{6}$ Hosobuchi Y. Direct surgical treatment of giant intracranial aneurysms. $J$ Neurosurg 1979;51:743-56.

${ }^{7}$ Sundt TM, Piepgras DG. Surgical approach to giant intracranial aneurysms. Operative experience with $\mathbf{8 0}$ cases. J Neurosurg 1979;56:731-42.

${ }^{8}$ Onuma T, Suzuki JL. Surgical treatment of giant intracranial aneurysms. $J$ Neurosurg 1979;51:33-6.

9 Lyell A. Large aneurysm of the circle of Willis with cure by spontaneous thrombosis. Br Med J 1936;2:282.

${ }^{10}$ Fodstad H, Liliequist B, Wirell S, et al. Giant serpentine intracranial aneurysm after carotid ligation. Case report. J Neurosurg 1978;49:903-9.

1 Segal HD, McLaurin RL. Giant serpentine aneurysm: report of two cases. J Neurosurg 1977;46:115-20.

${ }^{12}$ Whittle IR, Williams DB, Halmagyi GM, Besser M. Spontaneous thrombosis of giant aneurysm and ipsilateral carotid artery. $J$ Neurosurg 1982;56:287-9.

${ }^{13}$ Sadik AR, Budzilovich GN, Shulman K. Giant aneurysm of the middle cerebral artery: case report. J Neurosurg 1965;22:177-81.

14 Thauvoy C, Vandresse JH, Stroobandt et al. Accroisement progressif et thrombose d'un aneurysme de la communicante anterieure. Elude clinique, radiologique et histologique. Neurochirurgie 1978; 24:423-7.

${ }^{15}$ Black SPW, German WJ. Observations on the relationship between volume and size of the orifice of experimental aneurysms. J Neurosurg 1960;17:984-90.

16 Jain KK. Surgery for intracranial aneurysm: a review. Canad J Surg 1965;8:172-87.

${ }^{17}$ Bull JWD. Massive aneurysms at the base of the brain. Brain 1969;92:535-70.

${ }^{18}$ Sutherland GR, King ME, Peerless SJ, et al. Platelet interaction with giant intracranial aneurysm. $J$ Neurosurg 1982;56:53-61.

${ }^{19}$ Sakaki T, Kinugawa K, Tanigake T, et al. Embolism from intracranial aneurysms. $J$ Neurosurg 1980;53:300-4.

${ }^{20}$ Auld AW, Shafey A. Transient ischaemic attachs not produced by extracranial disease. South Med J 1976;69:722-4.

${ }^{21}$ Mehdorn HM, Chater NL, Townshend JJ, et al. Giant aneurysms and cerebral ischaemia. Surg Neurol 1980;13:49-57.

${ }^{22}$ Antunes JL, Correll JW. Cerebral emboli from intracranial aneurysms. Surg Neurol 1976;6:7-10.

${ }^{23}$ Robinson JL, Roberts A. Operative treatment of aneurysms and the Coanda effect. J Neurol Neurosurg Psychiatry 1972;35:804-9. 